\title{
How should clinicians rehabilitate patients after $A C L$ reconstruction? A systematic review of clinical practice guidelines (CPGs) with a focus on quality appraisal (AGREE II)
}

\author{
Renato Andrade (ㄷ) , 1,2,3 Rogério Pereira, ${ }^{1,2,3,4}$ Robert van Cingel, ${ }^{5,6} \mathrm{~J}$ Bart Staal, ${ }_{1}^{6,7}$ \\ João Espregueira-Mendes 1,2,8,9
}

- Additional material is published online only. To view please visit the journal online (http://dx.doi.org/10. 1136bjsports-2018-100310).

For numbered affiliations see end of article.

\section{Correspondence to} Renato Andrade, Clínica do Dragão, Espregueira-Mendes Sports Centre - FIFA Medical Centre of Excellence, Porto 4350-415, Portugal; randrade@espregueira.com

Accepted 15 May 2019 Published Online First 7 June 2019
Check for updates

(C) Author(s) (or their employer(s)) 2020. No commercial re-use. See rights and permissions. Published by BMJ.

To cite: Andrade $R_{\text {, }}$ Pereira $R$, van Cingel $R$, et al. Br J Sports Med 2020:54:512-519.

\begin{abstract}
Objectives To summarise recommendations and appraise the quality of international clinical practice guidelines (CPGs) for rehabilitation after $\mathrm{ACL}$ reconstruction.

Design Systematic review of CPGs (PROSPERO number: CRD42017020407).

Data sources Pubmed, EMBASE, Cochrane, SPORTDiscus, PEDro and grey literature databases were searched up to 30 September 2018.

Eligibility criteria English-language CPGs on rehabilitation following $A C L$ reconstruction that used systematic search of evidence to formulate recommendations.

Methods We followed the Preferred Reporting Items for Systematic Reviews and Meta-Analyses guidelines to report the systematic review. Two appraisers used the Appraisal of Guidelines for Research and Evaluation (AGREE) II instrument to report comprehensiveness, consistency and quality of CPGs. We summarised recommendations for rehabilitation after $\mathrm{ACL}$ reconstruction.
\end{abstract}

Results Six CPGs with an overall median AGREE II total score of 130 points (out of 168) and median overall quality of $63 \%$ were included. One CPG had an overall score below the $50 \%$ (poor quality score) and two CPGs scored above $80 \%$ (higher quality score). The lowest domain score was 'applicability' (can clinicians implement this in practice?) (29\%) and the highest 'scope and purpose' (78\%) and 'clarity of presentation' (75\%). CPGs recommended immediate knee mobilisation and strength/neuromuscular training. Early full weight-bearing exercises, early open and closed kinetic-chain exercises, cryotherapy and neuromuscular electrostimulation may be used according individual circumstances. The CPGs recommend against continuous passive motion and functional bracing.

Conclusion The quality of the CPGs in ACL postoperative rehabilitation was good, but all CPGs showed poor applicability. Immediate knee mobilisation and strength/neuromuscular training should be used. Continuous passive motion and functional bracing should be eschewed.

\section{INTRODUCTION}

Anterior cruciate ligament (ACL) reconstructive surgery is a very common operation. ${ }^{1}$ Patients may choose ACL reconstruction because they believe it may increase their likelihood of returning to competitive sport $^{2}$ and that it may mitigate the risk of post-traumatic knee osteoarthritis. ${ }^{3}$ However, not all patients return to sports, ${ }^{4}$ many experience impaired long-term knee-related quality of life, ${ }^{5}$ and $35 \%$ of patients develop tibiofemoral symptomatic osteoarthritis 10 years after ACL reconstruction. ${ }^{6}$

Around $80 \%$ of ACL-reconstructed patients return to some kind of sporting activities, but only $65 \%$ return to their preinjury level and 55\% to competitive level sports. ${ }^{4}$ There are data that inadequate rehabilitation combined with an unprepared return to sports ${ }^{7-9}$ may limit subsequent sporting performance and predispose to reinjury (ACL, other knee injuries and perhaps other injuries). Returning to high-level competitive pivoting sports after ACL reconstruction is associated with a more than fourfold increase in reinjury rates over the subsequent 2 years $^{7}$ and about $20 \%$ of athletes who return to sport experience a second ACL injury. ${ }^{10}$

Rehabilitation may promote successful return to preinjury sporting activities. Clinicians follow specific stepwise progression rehabilitation criteria and rely on several clinical and impairment-based criteria before allowing patients to return to sports. ${ }^{7} 811-13$ There is substantial heterogeneity in the ACL rehabilitation protocols available online ${ }^{14}$ and in the scientific literature. ${ }^{15-19}$ Criteria for when to let the athletes progress are not standardised and experts disagree on the choice of follow-up patient-reported and physical performance-based outcome measures. ${ }^{19}{ }^{20}$ There is no agreement on the key criteria that should be met before return to sport. ${ }^{1121-23}$

We examined the availability, consistency and quality of clinical practice guidelines (CPGs) for individuals who underwent ACL reconstruction. Our systematic review aimed to summarise recommendations and appraise the quality of internationally available ACL postoperative rehabilitation CPGs.

\section{METHODS}

The systematic review was conducted according the Preferred Reporting Items for Systematic Reviews and Meta-Analyses (PRISMA) statement. $^{24}$ The review protocol was registered prospectively at the International Prospective Register of Systematic Reviews (PROSPERO) under the identification number CRD42017020407.

\section{Search strategy}

We conducted a comprehensive database search using PubMed, EMBASE, Cochrane Library, 
SPORTDiscus and PEDro to search CPGs that presented rehabilitation CPGs of ACL injuries. To search grey literature and CPGs repositories we used the OpenGrey, National Guideline Clearinghouse of the Agency for Healthcare Research and Quality, Guidelines International Network (G-I-N) and National Institute for Health for Health and Care Excellence (NICE) databases. Two authors (RA and RP) independently performed all searches up to the 30 September of 2018 and matched results to check for overlap. A third author $(\mathrm{RvC})$ resolved any disagreements. The reference lists of most relevant CPGs and review articles was scanned for additional CPGs. The database search strategy combined the following search terms: physiotherapy; 'physical therapy'; kinesiotherapy; rehabilitation; treatment; intervention; exercise; 'exercise therapy'; 'postoperative care'; 'resistance training'; 'strength training'; 'neuromuscular training'; ACL; 'anterior cruciate ligament'; guidelines; evidence-based; 'systematic review'. Online supplement 1 presents an example of the search strategy. We contacted worldwide experts via email on ACL rehabilitation regarding their knowledge of any further potentially eligible CPGs. We also performed a hand search in Google with the term 'anterior cruciate ligament rehabilitation' in English and translated into other languages (eg, Finnish, Norwegian, Swedish and Danish) to increase the spectrum of results. For any CPGs found in languages other than English, we searched for a translated version and contacted the authors of the CPG (if email was available) to request an English-translated version. We found an ACL rehabilitation CPG from the Physical Therapy Association of Japan ${ }^{25}$ written in Japanese language, but an English version was not found and the corresponding author's email was not available.

\section{Study selection}

All records were exported to EndNote X7 (Thomson and Reuters) and duplicates were removed using the software command 'find duplicates' and by manual checking. We screened all nonduplicated titles and abstracts for relevant articles and retrieved the full text of potentially relevant CPGs for further analysis. The full texts were examined according the following inclusion criteria: (1) CPGs had to be developed by a panel of multidisciplinary experts and defined as 'statements that include recommendations intended to optimise patient care that are informed by a systematic review of evidence and an assessment of the benefits and harms of alternative care options ${ }^{26}$; (2) CPGs must report on the postoperative rehabilitation of patients following ACL reconstruction; (3) CPGs must be available in English; and (4) CPGs must include a systematic review of the current scientific literature to formulate their recommendations. By 'postoperative rehabilitation', we refer to both the postoperative early management and active rehabilitation phases. We excluded all CPGs for: (1) conservative treatment of knee injuries; (2) rehabilitation of knee injuries, without specific recommendation for rehabilitation after ACL reconstruction; (3) skeletally immature populations; and (4) and those that were exclusive to the orthopaedic surgical treatment of ACL injuries without including recommendations for postoperative rehabilitation.

\section{Data extraction and summary}

One author (RA) performed the data collection and extraction, which was checked for consistency by another author (RP). All documents related to the CPGs (full CPG document, appendices, supplementary material and journal publications) were collected for analysis. We extracted and summarised the characteristics of the CPG and recommendations on specific rehabilitation interventions, postoperative follow-up assessment and return to sport criteria. For extraction and summary purposes, we considered 'accelerated rehabilitation' the use of more aggressive rehabilitation (such as immediate knee mobilisation, early full weight bearing or early open and closed kinetic chain exercises) aiming a sooner return to sport. We classified the recommendations as: 'should be used' when there was a strong recommendation that the intervention/criteria should be applied; 'may be used' when the recommendation was not strong or the CPGs authors used the terms 'may/might be used' or 'can/could be used'; 'should not be used' when there was a clear recommendation to not use the intervention/criteria; and 'uncertain recommendation' when the recommendation was not clear.

\section{Quality appraisal of the CPGs}

The Appraisal of Guidelines for Research and Evaluation (AGREE) II instrument, created by the AGREE Collaboration, is a 23-item tool, organised within six domains and two global rating items ('overall assessment'). An international validation study showed acceptable reliability (Cronbach alpha) for most domains, varying from 0.64 to $0.88 .{ }^{27}$ Each domain assesses a single dimension of guideline quality, comprising: scope and purpose; stakeholder involvement; rigour of development; clarity of presentation; applicability; editorial independence. ${ }^{28}$ Each item is scored using a seven-point Likert scale according the AGREE II user's manual guidance and criteria suggested for each item. The domain score is calculated summing all the scores of the individual items in a domain and by scaling the total as a percentage of the maximum possible score for that domain. The same procedure is performed for the total overall score, using the total domain scores for the computation. As previously suggested, we considered domain and overall scores under 50\% to indicate lower quality. ${ }^{29-31}$ Two academic and practising physiotherapists (RA and RP) performed the methodological quality appraisals independently according to the AGREE II instrument. ${ }^{28}$ Before each AGREE II domain assessment, a meeting was held to discuss the appraisal criteria according to the AGREE II manual and training tools.

\section{Statistical analysis}

All data were analysed using the SPSS V.25.0 software. Median and interquartile rande (IQR) were computed for the domain scores and total scores. The inter-rater agreement was computed using the intraclass correlation coefficient (ICC) with two-way random effects model was computed for each domain and total score. The level of agreement (ICC) was classified according to commonly cited cut-offs: poor $(<0.40)$, fair $(0.40-0.59)$, good $(0.60-0.74)$ or excellent $(0.75-1.00) .^{32}$

\section{RESULTS}

\section{Study selection}

The database and hand-search yielded 1167 titles and abstracts. Duplicated articles were removed and 758 articles were screened based on their title and abstract. A total of 50 full-text articles were screened for eligibility and six CPGs met the eligibility criteria and were included in our systematic review (figure 1).

\section{CPGs characteristics}

The table 1 displays the CPGs' characteristics and their development methods. Three CPGs were originally from the USA, ${ }^{33-35}$ two from the Netherlands ${ }^{3637}$ and one from New Zealand. ${ }^{38}$ CPGs were issued by the following national and international orthopaedic and physical therapy associations: American 


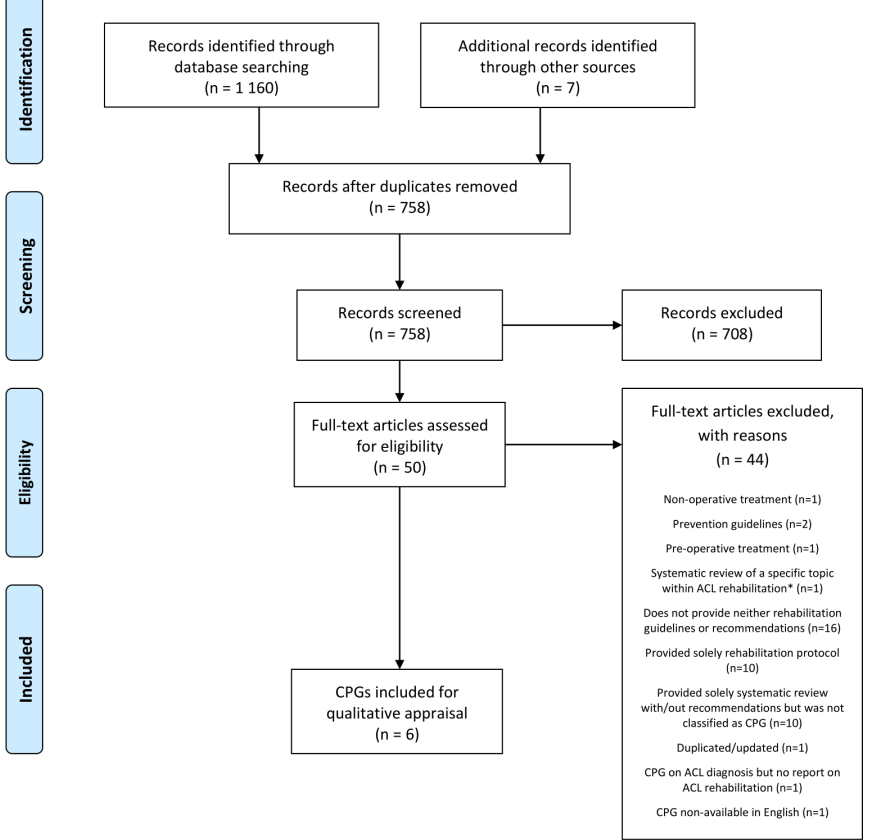

* Specific topics include: Neuromuscular Electrical Stimulation, Cryotherapy and Strength Training.

Figure 1 Preferred Reporting Items for Systematic Reviews and MetaAnalyses flow chart for the database search.

Physical Therapy Association (APTA) ${ }^{35}$; Dutch Orthopaedic Association $(\mathrm{DOA})^{36}$; Multicenter Orthopaedic Outcomes Network $(\mathrm{MOON})^{34}$; American Academy of Orthopaedic Surgeons (AAOS) ${ }^{33}$; Royal Dutch Society for Physical Therapy $(\mathrm{KNGF})^{37}$ and New Zealand Guidelines Group (NZGG). ${ }^{38}$

All CPGs included physical therapists and/or orthopaedic surgeons in their multidisciplinary guideline panel. ${ }^{33-38}$ Sports medicine physicians, researchers or experts, ${ }^{33-38}$ athletic trainers, ${ }^{33}$ musculoskeletal radiologists, ${ }^{38}$ public health professionals, ${ }^{38}$ psychologists, ${ }^{38}$ pain specialists, ${ }^{38}$ medical professional quality assessors ${ }^{36}$ and patients ${ }^{38}$ were also included in the multidisciplinary teams. The target groups included mostly physical therapists, orthopaedic surgeons and physicians involved in the treatment of ACL injuries. ${ }^{33}{ }^{35-37}$ Four CPGs also included consumers (patients, insurance payers and health-policy decision-makers) as a target group. ${ }^{33-35} 38$

The scientific literature search and inclusion criteria varied among CPGs. Only one CPG (MOON) ${ }^{34}$ restricted the inclusion criteria to randomised clinical trials, while two other CPGs (KNGF, NZGG) ${ }^{37} 38$ allowed meta-analyses, systematic reviews, randomised controlled trials (RCTs) and prospective cohort studies to be included. The remaining three CPGs (AAOS, APTA, DOA) $)^{33} 35$ used data sources ranging from RCTs to cohort clinical studies, ${ }^{33}$ case-control studies ${ }^{36}$ or case series. ${ }^{35}$ The criteria used to grade evidence were heterogeneous and each CPG reported a different method, including the following systems: Oxford Centre Evidence-Based Medicine; Scottish Intercollegiate Guidelines Network Grading System (SIGN); Grading of Recommendations Assessment, Development and Evaluation (GRADE) and EBRO (a Dutch grading system that was a predecessor to GRADE). ${ }^{39}$ Four CPGs graded the strength of their recommendations into four different levels based on the level of evidence of the studies selected for the recommendations (AAOS, DOA, KNGF, NZGG), ${ }^{33}$ but each CPG used different criteria to rate the strength of the recommendations. One CPG (APTA) ${ }^{35}$ used six levels including theoretical/ foundational evidence (basic science, animal and cadaveric research) and consensus expert opinions. Conversely, there was one CPG $(\mathrm{MOON})^{34}$ that did not grade recommendations but only included randomised clinical trials.

\section{Overall appraisal of the CPGs}

The median total score of AGREE II for the CPGs was 130 points (out of 180), with a median overall quality of $63 \%$ (IQR, $48 \%-83 \%$ ). One CPG (DOA) ${ }^{36}$ had an overall score below $50 \%$ and two CPGs (AAOS, APTA) 3335 scored above $80 \%$ (table 2). The lowest domain score was for 'applicability' (domain 5), with a median score of 29\% (IQR, 8\%-39\%). The domains with highest score were 'scope and purpose' (domain 1) with a median score of 78\% (IQR 34\%-83\%) and 'clarity of presentation' (domain 4), with a median score of 75\% (IQR, 59\%-90\%). The lowest mean scores ( $\leq 3$ points) for individual items included: 'the views and preferences of the target population (patients, public, etc) have been sought' (Item 5); 'the guideline has been externally reviewed by experts prior to its publication' (Item 13); 'the guideline describes facilitators and barriers to its application' (Item 18); 'the potential resource implications of applying the recommendations have been considered' (Item 20); 'the guideline presents monitoring and/or auditing criteria' (Item 21). Inter-rater reliability was excellent for all domains and overall scores (table 3 ). Online supplement 2 displays the individual scoring of AGREE II for each CPG.

\section{Rehabilitation recommendations reported in the CPGs}

The recommendations from all six CPGs are summarised in table 4. One CPG $(\mathrm{NZGG})^{38}$ suggested that intensive rehabilitation may be used in some cases and two CPGs (MOON, KNGF) ${ }^{34} 37$ suggested that home-based rehabilitation may be used in motivated patients. One CPG (APTA) ${ }^{35}$ recommended a combination of ambulatory and home-based supervised exercises. Three guidelines (AAOS, MOON, NZGG) 333438 provided uncertain recommendation for the use of accelerated over nonaccelerated protocols One CPG $(\mathrm{KNGF})^{37}$ recommended that progressive goal-based rehabilitation rather than time-based rehabilitation should be used.

We found consistent recommendations across the CPGs that immediate knee mobilisation (MOON, APTA) (34 $35^{3}$ and strength/ neuromuscular training (MOON, APTA, DOA, KNGF) $)^{34-37}$ should be used. Two CPGs (MOON, KNGF) ${ }^{34} 37$ recommended the use of early full weight-bearing exercises and one CPG $(\mathrm{APTA})^{35}$ suggested that these may be used in the immediate postoperative period as tolerated. Cryotherapy was recommended in one CPG (APTA) ${ }^{35}$ and another CPG (KNGF) ${ }^{37}$ suggested that it may be used in the first postoperative weeks. Neuromuscular electrostimulation was either recommended to be used in the first 6-8 weeks following ACL reconstruction (APTA) ${ }^{35}$ or suggested to be added to isometric training and according the clinician's preferences (MOON, KNGF). ${ }^{3437}$ Both open and closed kineticchain exercises may be used (APTA, DOA, KNGF, NZGG). ${ }^{35-38}$ In early phases of rehabilitation, closed kinetic-chain exercises should be prioritised $(\mathrm{MOON})^{34}$ and open kinetic-chain exercises $\left(90-45^{\circ}\right)$ may be introduced as early as four postoperative weeks (KNGF, NZGG). ${ }^{37} 38 \mathrm{CPG}$ recommended against adding continuous passive motion $(\mathrm{MOON})^{34}$ or postoperative functional bracing (AAOS, MOON, DOA, NZGG) 33343638 to ACL postoperative rehabilitation. One CPG (APTA) ${ }^{35}$ suggested that continuous passive motion may be used in the immediate postoperative period and that knee bracing may be used according the patient's preferences or associated ligament injuries (although supported by weak evidence). 
Table 1 CPGs characteristics and development methods for recommendations

\begin{tabular}{|c|c|c|c|c|c|c|c|c|}
\hline First author & Year & Country & $\begin{array}{l}\text { Organisational } \\
\text { affiliation }\end{array}$ & Journal & Multidisciplinary team & Target group & Evidence based & Grading system \\
\hline Arroll ${ }^{38}$ & 2003 & New Zealand & NZGG* & $\begin{array}{l}\text { External } \\
\text { document }\end{array}$ & $\begin{array}{l}\text { Four PTs; one MSK } \\
\text { radiologist; one public } \\
\text { health; four OSs; six non- } \\
\text { specified medical doctors; } \\
\text { one pain specialist; one } \\
\text { psychologist; two sports } \\
\text { physicians; two consumers }\end{array}$ & $\begin{array}{l}\text { Health professionals and } \\
\text { consumers }\end{array}$ & $\begin{array}{l}\text { Systematic review of } \\
\text { systematic reviews, meta- } \\
\text { analysis, RCTs or quasi- } \\
\text { RCTs }\end{array}$ & $\begin{array}{l}\text { Studies: SIGN } \\
\text { (revised) } \\
\text { Recomm: A-C, I }\end{array}$ \\
\hline Meuffels ${ }^{36}$ & 2012 & Netherlands & $\begin{array}{l}\text { Dutch } \\
\text { Orthopaedic } \\
\text { Association }\end{array}$ & Acta Orthop & $\begin{array}{l}\text { Two PTs; eight OSs; one } \\
\text { sports medicine expert; } \\
\text { two medical professional } \\
\text { quality assessors }\end{array}$ & $\begin{array}{l}\text { All members of medical } \\
\text { disciplines concerned with } \\
\text { diagnosis and treatment of } \\
\text { ACL injuries }\end{array}$ & $\begin{array}{l}\text { Search for existing } \\
\text { guidelines and systematic } \\
\text { review for RCTs and } \\
\text { systematic reviews. When } \\
\text { insufficient data, systematic } \\
\text { review of case-control and } \\
\text { cohort studies. }\end{array}$ & $\begin{array}{l}\text { Studies: A1, A2, } \\
\text { B, C, D } \\
\text { Recomm: 1-4 }\end{array}$ \\
\hline Wright $^{34}$ & 2014 & USA & MOON & Sports Health & $\begin{array}{l}\text { Seven PTs; twenty-one } \\
\text { OSs; four sports medicine } \\
\text { researchers/experts }\end{array}$ & $\begin{array}{l}\text { Practicing PTs and ACL- } \\
\text { injured people (from } \\
\text { nonathlete to elite athlete) }\end{array}$ & $\begin{array}{l}\text { Systematic reviews of level } \\
\text { I and level II evidence }\end{array}$ & $\begin{array}{l}\text { No criteria, solely } \\
\text { based on the } \\
\text { included RCTs }\end{array}$ \\
\hline Shea ${ }^{33}$ & 2015 & USA & AAOSt & $\begin{array}{l}\text { JAm Acad } \\
\text { Orthop Surg } \\
\text { J Bone Joint } \\
\text { Surg Am } \\
\\
\text { External } \\
\text { document }\end{array}$ & $\begin{array}{l}\text { Twelve OSs; one athletic } \\
\text { trainer; one sports } \\
\text { medicine expert }\end{array}$ & $\begin{array}{l}\text { OSs and physicians } \\
\text { managing patients with } \\
\text { ACL injuries and other } \\
\text { stakeholder involved } \\
\text { (insurance payers, } \\
\text { governmental bodies, health } \\
\text { policy decision makers and } \\
\text { other related healthcare } \\
\text { professionals) }\end{array}$ & $\begin{array}{l}\text { Systematic review of } \\
\text { clinical cohort studies }\end{array}$ & $\begin{array}{l}\text { Studies: adapted } \\
\text { from GRADE } \\
\text { Recomm: } 1-4\end{array}$ \\
\hline van Melick ${ }^{37}$ & 2016 & Netherlands & KNGF & $\begin{array}{l}\text { Br J Sports } \\
\text { Med }\end{array}$ & $\begin{array}{l}\text { Three PTs; one OSs; one } \\
\text { trauma surgeon; one sports } \\
\text { medicine expert }\end{array}$ & $\begin{array}{l}\text { PTs involved in } \\
\text { rehabilitation after ACL } \\
\text { reconstruction }\end{array}$ & $\begin{array}{l}\text { Systematic review of } \\
\text { systematic reviews, } \\
\text { meta-analysis, RCTs and } \\
\text { prospective cohort studies }\end{array}$ & $\begin{array}{l}\text { Studies: EBRO } \\
\text { Recomm: 1-4 (EBRO) }\end{array}$ \\
\hline Logerstedt ${ }^{35}$ & 2017 & USA & APTA & $\begin{array}{l}\text { J Orthop Sports } \\
\text { Phys Ther }\end{array}$ & $\begin{array}{l}\text { Five PTs; three OSs; one } \\
\text { sports medicine expert }\end{array}$ & $\begin{array}{l}\text { Policymakers, payers, } \\
\text { orthopaedic PTs, } \\
\text { orthopaedic PT clinicians, } \\
\text { academic instructors, clinical } \\
\text { instructors, students, interns, } \\
\text { residents, and fellows }\end{array}$ & $\begin{array}{l}\text { Systematic review of } \\
\text { systematic reviews, meta- } \\
\text { analyses, experimental and } \\
\text { quasi-experimental, cohort, } \\
\text { case series, and cross- } \\
\text { sectional studies }\end{array}$ & $\begin{array}{l}\text { Studies: I-V (CEBM) } \\
\text { Recomm: A-F }\end{array}$ \\
\hline
\end{tabular}

${ }^{*}$ Has received endorsement from Arthritis New Zealand; Effective Practice, Informatics and Quality Improvement (EPIQ); New Zealand Society of Physiotherapists; NZ Association of Musculoskeletal Medicine; Royal Australian and New Zealand College of Radiologist; Royal New Zealand College of General Practitioners; Sports Medicine New Zealand; The New Zealand Orthopaedic Association.

tHas received inputs from the National Athletic Trainer's Association, American Academy of Physical Medicine and Rehabilitation, American College of Sports Medicine, American Medical Society for Sports Medicine, American Orthopaedic Society for Sports Medicine and the National Academy of Sports Medicine.

AAOS, American Academy of Orthopaedic Surgeons; APTA, American Physical Therapy Association; CEBM, Centre Evidence-Based Medicine (Oxford); CPG, clinical practice guidelines; EBRO, Evidence- Based Richtkijn (Guideline) Ontwikkeling (Development); GRADE, Grading of Recommendations Assessment, Development, and Evaluation; KNGF, Royal Dutch Society for Physical Therapy; MOON, Multicenter Orthopaedic Outcomes Network; MSK, musculoskeletal; OSs, orthopaedic surgeons; PTs, physical therapists; RCTs, randomised controlled trials; Recomm, recommendations.

Patient-reported outcome measures (clinical and functional), psychological and general health questionnaires and level of activity scales were recommended to be used to follow the patient's rehabilitation progress and status (AAOS, APTA, DOA, KNGF). ${ }^{33}{ }^{35-37}$ The table 5 summarises the recommended patient-reported outcome measures and functional testing to assess the patient's status and guide rehabilitation progression. While one CPG $(\mathrm{AAOS})^{35}$ provided uncertain recommendation about waiting a specific postoperative time or achieving a specific goal to allow the patient return to sports participation, two CPGs (APTA and KNGF) ${ }^{35} 37$ recommended to use multidimensional criteria-based and one $(\mathrm{DOA})^{36}$ a time-based return to sports strategy (table 4). The table 5 summarises both the specific evidence based and non-evidence-based discharge criteria for returning to sport that were included in the CPGs or their respective postoperative rehabilitation protocol. Return

Table 2 AGREE II domain and total scores for the included CPGs

\begin{tabular}{|c|c|c|c|c|c|c|c|c|}
\hline CPG & $\begin{array}{l}\text { Domain 1: } \\
\text { scope and } \\
\text { purpose }\end{array}$ & $\begin{array}{l}\text { Domain 2: } \\
\text { stakeholder } \\
\text { involvement }\end{array}$ & $\begin{array}{l}\text { Domain 3: rigour } \\
\text { of development }\end{array}$ & $\begin{array}{l}\text { Domain 4: clarity } \\
\text { of presentation }\end{array}$ & $\begin{array}{l}\text { Domain 5: } \\
\text { applicability }\end{array}$ & $\begin{array}{l}\text { Domain 6: } \\
\text { editorial } \\
\text { independence }\end{array}$ & Overall quality & Total score \\
\hline $\mathrm{NZGG}^{38}$ & 27.8 & 58.3 & 59.4 & 75.0 & 47.9 & 66.7 & 58.3 & 128.5 \\
\hline $\mathrm{DOA}^{36}$ & 83.3 & 41.7 & 39.6 & 61.1 & 0.0 & 0.0 & 41.7 & 93.1 \\
\hline $\mathrm{MOON}^{34}$ & 36.1 & 33.3 & 45.8 & 52.8 & 25.0 & 66.7 & 50.0 & 101.4 \\
\hline $\mathrm{AAOS}^{33}$ & 72.2 & 72.2 & 93.8 & 75.0 & 33.3 & 87.5 & 83.3 & 166.7 \\
\hline $\mathrm{KNGF}^{37}$ & 83.3 & 47.2 & 54.2 & 91.7 & 10.4 & 70.8 & 66.7 & 129.2 \\
\hline APTA $^{35}$ & 83.3 & 75.0 & 76.0 & 88.9 & 35.4 & 70.8 & 83.3 & 159.7 \\
\hline
\end{tabular}

AAOS, American Academy of Orthopaedic Surgeons; AGREE, Appraisal of Guidelines for Research and Evaluation; APTA, American Physical Therapy Association; CPG, clinical practice guideline; DOA, Dutch Orthopaedic Association; KNGF, Royal Dutch Society for Physical Therapy; MOON, Multicenter Orthopaedic Outcomes Network; NZGG, New Zealand Guidelines Group. 


$\begin{aligned} & \text { Table } 3 \\
& \text { reliability }\end{aligned}$
\begin{tabular}{lcl} 
Domain (maximum score) & Median score, \% (IQR) & ICC $(95 \%$ CI) \\
\hline Scope and purpose (21) & $78(34-83)$ & $0.87(0.26$ to 0.98$)$ \\
\hline Stakeholder involvement (21) & $53(40-73)$ & $0.98(0.77$ to 0.98$)$ \\
\hline Rigour of development (56) & $57(44-80)$ & $0.99(0.93$ to 0.99$)$ \\
\hline Clarity of presentation (21) & $75(59-90)$ & $0.80(0.00$ to 0.97$)$ \\
\hline Applicability (28) & $29(8-39)$ & $0.91(0.26$ to 0.99$)$ \\
\hline Editorial independence (14) & $69(50-75)$ & $0.99(0.94$ to 0.99$)$ \\
\hline Overall quality (7) & $63(48-83)$ & $0.92(0.52$ to 0.99$)$ \\
\hline Total score (168) & $130(99-161)$ & $0.98(0.06$ to 0.99$)$ \\
\hline AGREE Apprisa $)$
\end{tabular}

AGREE, Appraisal of Guidelines for Research and Evaluation; ICC, intraclass correlation.

to sport criteria often included a complete and extensive test battery of knee function and strength to assess the patient readiness to resume sports activities.

\section{DISCUSSION}

Which recommendations should clinicians follow?

From five high-quality CPGs, we conclude that immediate knee mobilisation and strength/neuromuscular training should be used during ACL postoperative rehabilitation. Early full weightbearing exercises, early open and closed kinetic chain exercises, cryotherapy and neuromuscular electrostimulation may be used according to individual circumstances. Guidelines recommend against continuous passive motion and functional bracing.

\section{What does this study mean for clinicians?}

CPGs consistently recommend the use of immediate knee mobilisation $^{34} 35$ and strength/neuromuscular training, ${ }^{34-37}$ following ACL reconstruction. Immediate mobilisation (within first week) is critical to increase joint range of motion, reduce knee pain and ward off soft tissue-related adverse events (eg, extension deficit). ${ }^{34} 35$ Clinicians should initiate isometric quadriceps strengthening exercises from the first postoperative week (if not causing pain) and shift progressively to concentric and eccentric (in closed kinetic chain) exercises. ${ }^{37}$ Strength training should be augmented with neuromuscular and motor control re-education exercises ${ }^{34-37}$ and may be complemented with supervised homebased rehabilitation in highly motivated patients. ${ }^{34} 3537$

Early (within first week) full weight bearing is encouraged but clinicians are advised to progress as tolerated. ${ }^{343537}$ Clinicians can use cryotherapy immediately after surgery to reduce knee pain ${ }^{3537}$ without increasing the risk of short-term adverse events (up to the first 48 hours). ${ }^{40}$ Neuromuscular electrostimulation can be added to isometric strengthening in the initial 6-8 weeks to re-educate voluntary contraction and increase strength of quadriceps muscles, ${ }^{34} 35{ }^{37}$ but the ideal electrical parameters remain elusive. Close kinetic chain exercises should be prioritised in the first postoperative month to mitigate the risk of patellofemoral pain and open kinetic chain exercises $\left(90-45^{\circ}\right)$ can be added as early as 4 weeks (but without extra weight in the first 12 weeks for hamstrings graft). ${ }^{34}{ }^{36-38}$ Further high-quality research is needed to ascertain the benefits of early full weightbearing exercises, cryotherapy, neuromuscular electrostimulation and early open and closed kinetic chain exercises in ACL postoperative rehabilitation.

Accelerated rehabilitation, aiming a sooner return to sport, was characterised in the CPGs as shorter period of rehabilitation, ${ }^{34}$ immediate knee mobilisation, ${ }^{33} 3538$ early weight bearing ${ }^{33} 38$ and early closed and open kinetic exercises. ${ }^{33} 38$ Although accelerated protocols were not prioritised over non-accelerated rehabilitation protocols, ${ }^{33} 34$ immediate knee mobilisation and early weight bearing (within first week) are recommended and have been the gold standard over the last two decades. We did not find a consensus of 'accelerated rehabilitation' definition. Future CPGs should provide a clearer definition of 'accelerated rehabilitation' and specify the timings they consider for immediate knee mobilisation and early full weight bearing.

The benefits of continuous passive motion ${ }^{34}$ or postoperative functional bracing ${ }^{34}$ are not supported by scientific evidence and clinicians should refrain from adding these interventions to the ACL postoperative rehabilitation. A knee brace may be considered if elicited by the patient or when there are other ligament injuries associated. ${ }^{35}$

'When should an athlete return to sport?' remains a complex question. CPGs recommend that clinicians should use chronobiological (graft biological healing), clinical (eg, KOOS, IKDC or Lysholm scores), functional (eg, battery of hop tests) and psychological (eg, ACL-RSI) milestones to progress on the rehabilitation process and to decide on the resumption to sport. ${ }^{34-37}$ Many dimensions of postoperative ACL rehabilitation (eg, dosage of interventions or progression criteria) and return to sport criteria are often lacking in the CPGs. Most CPGs do not spell out when athletes are ready to return to sport-this is an obvious elephant in the room that is overlooked in nearly all CPGs we examined. There are no clear criteria for 'highly likely to return to sport successfully' because data are lacking and the ideal study design (RCT that randomises patients to one set of criteria vs another) would be unethical. We encourage readers to consult the rehabilitation protocols published alongside the MOON and KNGF CPGs to access the dosage and timing of interventions, criteria-based rehabilitation progressions and return to sports criteria. We advise clinicians to complement the return to sport criteria with the recommendations underpinned by the 2016 consensus on return to sport. ${ }^{41}$

A high AGREE score indicates good quality of CPG development and comprehensiveness of reporting but does neither assess the scientific content nor clinical context adequacy of the CPGs. Although the AAOS $\mathrm{CPG}^{34}$ achieved the highest total quality score, it neither included physiotherapists in the development team nor reflected the full multidisciplinary rehabilitation course-that is, does not include a complete set of therapeutic strategies for ACL postoperative rehabilitation-and we therefore do not recommend it for postoperative ACL rehabilitation. The DOA CPG ${ }^{36}$ is also not recommended due to its low quality total score and as it does not represent the full multidisciplinary rehabilitation course. Nonetheless, these two CPGs were developed by orthopaedic associations and their scope and purpose was focused on the orthopaedic treatment rather than on ACL postoperative rehabilitation. The $\mathrm{NZGG}^{38}$ and APTA ${ }^{35}$ CPGs also addressed knee structures beyond the ACL, but has not influenced the recommendations. The NZGG $\mathrm{CPG}^{38}$ failed the timeline to update their document (partially due to the group voluntary liquidation in mid-2012) and should be considered as outdated. We encourage and endorse the use of MOON, ${ }^{34}$ $\mathrm{KNGF}^{37}$ and APTA ${ }^{35}$ CPGs as these include the full multidisciplinary ACL postoperative rehabilitation.

\section{Shortcomings of CPGs: how can we improve them?}

Our systematic review identified that applicability-the ease with which clinicians can implement the CPG recommendations into clinical daily practice-was the domain with the lowest quality. This domain is consistently low in other systematic reviews of CPGs on a wide range of healthcare topics. ${ }^{29} 304243$ CPGs failed to identify and describe the potential facilitators, barriers and cost 
Table 4 Recommendations on $\mathrm{ACL}$ rehabilitation and postoperative follow-up assessment.

\begin{tabular}{|c|c|c|c|c|c|c|}
\hline Recommendation item & $\mathrm{NZGG}^{38}$ & $\mathrm{DOA}^{36}$ & $\mathrm{MOON}^{34}$ & $\mathrm{AAOS}^{33}$ & KNGF $^{37}$ & APTA $^{35}$ \\
\hline \multirow[t]{2}{*}{$\begin{array}{l}\text { Supervised } \\
\text { rehabilitation vs } \\
\text { home-based exercises }\end{array}$} & \multirow[t]{2}{*}{$\begin{array}{l}\text { Intensive supervised } \\
\text { physical therapy may be } \\
\text { used in some cases. }\end{array}$} & \multirow[t]{2}{*}{-} & \multirow[t]{2}{*}{$\begin{array}{l}\text { Home-based } \\
\text { rehabilitation may } \\
\text { be used in motivated } \\
\text { patients. }\end{array}$} & \multirow[t]{2}{*}{-} & $\begin{array}{l}\text { Uncertain } \\
\text { recommendation on } \\
\text { supervised rehabilitation } \\
\text { versus home-based } \\
\text { exercises. }\end{array}$ & \multirow[t]{2}{*}{$\begin{array}{l}\text { Exercise ambulatory } \\
\text { programmes supplemented } \\
\text { by a prescribed home-based } \\
\text { programme supervised by } \\
\text { a physical therapist should } \\
\text { be used. }\end{array}$} \\
\hline & & & & & $\begin{array}{l}\text { A minimally supervised } \\
\text { rehabilitation may be } \\
\text { used in specific groups of } \\
\text { patients that are highly } \\
\text { motivated and live far } \\
\text { from a physical therapist. }\end{array}$ & \\
\hline $\begin{array}{l}\text { Accelerated } \\
\text { rehabilitation }\end{array}$ & $\begin{array}{l}\text { Uncertain } \\
\text { recommendation } \\
\text { on 'accelerated } \\
\text { rehabilitation } \\
\text { programmes'. }\end{array}$ & - & $\begin{array}{l}\text { Uncertain } \\
\text { recommendation on } \\
\text { 'accelerated rehabilitation } \\
\text { programmes'. }\end{array}$ & $\begin{array}{l}\text { Uncertain } \\
\text { recommendation } \\
\text { on 'accelerated } \\
\text { rehabilitation } \\
\text { programmes'. }\end{array}$ & $\begin{array}{l}\text { Prehabilitation and } \\
\text { progressive goal-based } \\
\text { rehabilitation rather than } \\
\text { time base should be used. }\end{array}$ & $\begin{array}{l}\text { Accelerated rehabilitation } \\
\text { characterised as 'immediate } \\
\text { knee mobilisation' should } \\
\text { be used. }\end{array}$ \\
\hline $\begin{array}{l}\text { Continuous passive } \\
\text { motion }\end{array}$ & - & - & $\begin{array}{l}\text { Continuous passive } \\
\text { motion is not } \\
\text { recommended. }\end{array}$ & - & - & $\begin{array}{l}\text { Continuous passive } \\
\text { motion may be used in the } \\
\text { immediate postoperative } \\
\text { period. }\end{array}$ \\
\hline ROM restrictions & - & - & $\begin{array}{l}\text { Immediate knee } \\
\text { mobilisation should } \\
\text { be used following ACL } \\
\text { reconstruction. }\end{array}$ & - & - & $\begin{array}{l}\text { Immediate knee } \\
\text { mobilisation (within } 1 \text { week, } \\
\text { should be used following } \\
\text { ACL reconstruction. }\end{array}$ \\
\hline $\begin{array}{l}\text { Weight bearing } \\
\text { restrictions }\end{array}$ & - & - & $\begin{array}{l}\text { Immediate full WB should } \\
\text { be used following ACL } \\
\text { reconstruction. }\end{array}$ & - & $\begin{array}{l}\text { Immediate WB should be } \\
\text { used after specific criteria } \\
\text { is fulfilled. }\end{array}$ & $\begin{array}{l}\text { Early WB (within } 1 \text { week) } \\
\text { may be used as tolerated. }\end{array}$ \\
\hline $\begin{array}{l}\text { Postoperative } \\
\text { functional bracing }\end{array}$ & $\begin{array}{l}\text { Postoperative knee brace } \\
\text { should not be used. }\end{array}$ & $\begin{array}{l}\text { Postoperative knee } \\
\text { brace should not be } \\
\text { used. }\end{array}$ & $\begin{array}{l}\text { Postoperative knee brace } \\
\text { should not be used. }\end{array}$ & $\begin{array}{l}\text { The routine use of } \\
\text { postoperative functional } \\
\text { knee brace should not } \\
\text { be used. }\end{array}$ & - & $\begin{array}{l}\text { Immediate postoperative } \\
\text { knee brace according to } \\
\text { patient's preferences or } \\
\text { associated ligament injuries. }\end{array}$ \\
\hline \multirow[t]{2}{*}{ OKC and CKC } & \multirow[t]{2}{*}{$\begin{array}{l}\text { OKC exercises }\left(90-45^{\circ}\right) \\
\text { may be used as early as } \\
4 \text { weeks. }\end{array}$} & \multirow{2}{*}{$\begin{array}{l}\text { Both OCK and CKC } \\
\text { exercises may be used } \\
\text { during strength training } \\
\text { but CKC should be } \\
\text { prioritised over OKC } \\
\text { exercises at the early } \\
\text { phase of rehabilitation. }\end{array}$} & $\begin{array}{l}\text { Uncertain } \\
\text { recommendation for OKC } \\
\text { exercises in earlier stages } \\
\text { of the rehabilitation. }\end{array}$ & \multirow[t]{2}{*}{-} & \multirow[t]{2}{*}{$\begin{array}{l}\text { Both OKC and CKC } \\
\text { exercises may be used. } \\
\text { OKC exercises }\left(90-45^{\circ}\right) \\
\text { may be used as early as } \\
4 \text { weeks. }\end{array}$} & \multirow[t]{2}{*}{-} \\
\hline & & & $\begin{array}{l}\text { OKC exercises may } \\
\text { be used after } 6 \\
\text { postoperative weeks }\end{array}$ & & & \\
\hline $\begin{array}{l}\text { Strength and } \\
\text { neuromuscular } \\
\text { training }\end{array}$ & - & $\begin{array}{l}\text { The combination } \\
\text { of strength and } \\
\text { neuromuscular training } \\
\text { should be used in } \\
\text { the postoperative } \\
\text { rehabilitation. }\end{array}$ & $\begin{array}{l}\text { Neuromuscular } \\
\text { training should be } \\
\text { used in most phases } \\
\text { of ACL postoperative } \\
\text { rehabilitation. }\end{array}$ & - & $\begin{array}{l}\text { Isometric quadriceps } \\
\text { exercises should be } \\
\text { used from the first } \\
\text { postoperative week. } \\
\text { Eccentric (in CKC) and } \\
\text { concentric quadriceps } \\
\text { training should be } \\
\text { used from the third } \\
\text { postoperative week. } \\
\text { Neuromuscular exercises } \\
\text { should be used in addition } \\
\text { to strength training. }\end{array}$ & $\begin{array}{l}\text { WB and non-WB concentric } \\
\text { and eccentric exercises } \\
\text { should be used from } 4 \text { to } 6 \\
\text { postoperative weeks ( } 2-3 \times / \\
\text { week during } 6-10 \text { months). } \\
\text { Neuromuscular re-education } \\
\text { training should be used } \\
\text { in addition to muscle } \\
\text { strengthening exercises. }\end{array}$ \\
\hline $\begin{array}{l}\text { Neuromuscular } \\
\text { electrostimulation }\end{array}$ & - & - & $\begin{array}{l}\text { NMES may be used } \\
\text { according to the } \\
\text { clinician's preference. }\end{array}$ & - & $\begin{array}{l}\text { NMES may be used in } \\
\text { addition to isometric } \\
\text { strength training at the } \\
\text { first postoperative weeks }\end{array}$ & $\begin{array}{l}\text { NMES should be used for } \\
\text { the initial 6-8 postoperative } \\
\text { weeks. }\end{array}$ \\
\hline Cryotherapy & - & - & - & - & $\begin{array}{l}\text { Cryotherapy may be used } \\
\text { in the first postoperative } \\
\text { week. }\end{array}$ & $\begin{array}{l}\text { Immediate cryotherapy } \\
\text { should be used. }\end{array}$ \\
\hline $\begin{array}{l}\text { Outcomes and/or } \\
\text { functional testing }\end{array}$ & - & $\begin{array}{l}\text { The combination of } \\
\text { clinical (Lachman, pivot } \\
\text { shift and anterior drawer } \\
\text { tests) and patient- } \\
\text { reported } \\
\text { Outcomes measures } \\
\text { (IKDC subjective and } \\
\text { KOOS) should be used. } \\
\text { Tegner score may be } \\
\text { used for measurement } \\
\text { of activity. }\end{array}$ & - & $\begin{array}{l}\text { Measures of knee pain, } \\
\text { activities of daily living, } \\
\text { quality of life, functional } \\
\text { status, activity tolerance } \\
\text { and self-reported } \\
\text { physical function } \\
\text { assessment should be } \\
\text { used. }\end{array}$ & $\begin{array}{l}\text { Psychological changes } \\
\text { during rehabilitation with } \\
\text { objective instruments } \\
\text { should be used. }\end{array}$ & $\begin{array}{l}\text { A combination of validated } \\
\text { patient-reported outcome } \\
\text { measures (IKDC } 2000 \text { or } \\
\text { KOOS), activity level tool } \\
\text { (Tegner or Marx) and a } \\
\text { psychological questionnaire } \\
\text { (ACL-RSI) should be used. } \\
\text { Functional performance } \\
\text { assessment (appropriated } \\
\text { clinical or field testing) } \\
\text { should be used. }\end{array}$ \\
\hline
\end{tabular}


Table 4 Continued

\begin{tabular}{|c|c|c|c|c|c|c|}
\hline Recommendation item & $\mathrm{NZGG}^{38}$ & $\mathrm{DOA}^{36}$ & MOON $^{34}$ & $\mathrm{AAOS}^{33}$ & $\mathrm{KNGF}^{37}$ & APTA $^{35}$ \\
\hline RTS criteria & - & $\begin{array}{l}\text { A minimum } 3 \text { month } \\
\text { cut-off to resume heavy } \\
\text { physical activity in } \\
\text { labour or sports should } \\
\text { be used. }\end{array}$ & - & $\begin{array}{l}\text { Uncertain } \\
\text { recommendation on } \\
\text { waiting for a specific } \\
\text { time or achieving a } \\
\text { specific functional goal } \\
\text { prior to return to sport. }\end{array}$ & $\begin{array}{l}\text { An extensive test battery } \\
\text { for assessing quantity } \\
\text { and quality of movement } \\
\text { should be used. } \\
\text { LSI of }>90 \% \text { for cut-off } \\
\text { point may be used may } \\
\text { be used for strength and } \\
\text { hop tests. } \\
\text { For pivoting/contact } \\
\text { sports, an LSI of } \geq 100 \% \\
\text { should be used. }\end{array}$ & $\begin{array}{l}\text { Functional testing to } \\
\text { determine a patient's } \\
\text { readiness to return to } \\
\text { activities should be used }\end{array}$ \\
\hline
\end{tabular}

Colour coding: Green, 'should be used'; Yellow, 'may be used'; Dark red, 'should not be used'; Light red, 'uncertain recommendation'.

AAOS, American Academy of Orthopaedic Surgeons; ACL, anterior cruciate ligament; ACL-RSI, anterior cruciate ligament - return to sport after injury; APTA, American Physical Therapy Association; CKC, closed kinetic chain; CPG, clinical practice guideline; DOA, Dutch Orthopaedic Association; IKDC, International Knee Documentation Committee; KNGF, Royal Dutch Society for Physical Therapy; KOOS, Knee injury and Osteoarthritis Outcome Score; LSI, Limb Symmetry Index; MOON, Multicenter Orthopaedic Outcomes Network; NMES, neuromuscular electrical stimulation; NR, non-reported; NZGG, New Zealand Guidelines Group; OKC, open kinetic chain; ROM, range of movement; RTS, return to sport; WB, weight bearing.

implications of applying their recommendations. Misreporting or insufficient know-how on identifying facilitators (eg, educational strategies) and barriers (eg, patient compliance, economic constrains or sociopolitical contexts) for CPG uptake are some possible reasons as those factors often lie beyond the skills of CPG development team members. ${ }^{42}$ Advice on marketing materials for promoters, procedures to promote CPGs' awareness and implementation, user-friendly educational tools, monitoring indicators and auditing criteria are often overlooked by CPGs. CPG developers should consider infographics ${ }^{44} 45$ and e-Health emerging methods ${ }^{46}$ (such as, mHealth technologies ${ }^{47} 48$ and online educational videos ${ }^{49}$ or 'living' documents ${ }^{50}$ ) to increase user awareness and ease the CPG uptake.

We acknowledge that compliance/adherence with rehabilitation protocols complicates this field of research. CPGs will only be helpful if they are based on sound evidence and advice is adopted. This field is ripe for implementation science approaches - this modern discipline should be included in planning, developing and implementing CPGs.

Most of the CPGs failed to report on the external expert/advisory panel revisions and how their feedback contributed to the recommendations' formulation, which is important for transparency and credibility. CPGs would benefit from a more rigorous and standardised method to formulate recommendations, and prevent the use of ambiguous recommendations (previously referred as 'may be used' or 'uncertain recommendations').

Patients' and stakeholders' involvement was often not fully addressed which may hinder optimal CPG development and compromise future patient engagement. ${ }^{52}$ CPGs should involve patients and the full spectrum of stakeholders as clinicians of various stripes, insurance payers and funders, health-policy decision-makers, service workers, researchers and expert CPG

Table 5 Recommended postoperative follow-up patient-reported outcome measures and return to play allowance criteria comprising different measurement methods

\begin{tabular}{|c|c|c|c|c|c|}
\hline \multirow[b]{2}{*}{ CPG } & \multicolumn{2}{|c|}{ Postoperative follow-up assessment } & \multicolumn{3}{|l|}{ Return to sport criteria } \\
\hline & PROMs & Functional testing & Isokinetic (strength) & Functional performance & Other \\
\hline $\mathrm{NZGG}^{38}$ & NR & NR & NR & NR & NR \\
\hline $\mathrm{DOA}^{36}$ & $\begin{array}{l}\text { KOOS } \\
\text { IKDC } \\
\text { Tegner Activity Level } \\
\text { Scale (low evidence) }\end{array}$ & NR & NR & NR & $\begin{array}{l}\text { Time-based criterion of at } \\
\text { least } 3 \text { months }\end{array}$ \\
\hline $\mathrm{MOON}^{34}$ & NR & NR & NR & $\begin{array}{l}\text { No functional complaints. } \\
\text { LSI>85\% (single hop, triple } \\
\text { hop, crossover hop and 6-metre } \\
\text { timed-hop) }\end{array}$ & $\begin{array}{l}\text { Confidence when running, } \\
\text { cutting and jumping at full } \\
\text { speed; } \\
\text { IKDC Question } \# 10 \geq 9\end{array}$ \\
\hline $\mathrm{AAOS}^{33}$ & NR & NR & NR & NR & NR \\
\hline $\mathrm{KNGF}^{37}$ & $\begin{array}{l}\text { IKDC } \\
\text { KOOS } \\
\text { TSK-11 } \\
\text { ACL-RSI } \\
\text { K-SES }\end{array}$ & $\begin{array}{l}\text { Isokinetic muscle strength } \\
\text { Hop test LSI } \\
\text { Drop Jump }\end{array}$ & $\begin{array}{l}\text { LSI }>90 \% \\
\text { LSI }>100 \% \text { for pivoting/ } \\
\text { contact sports }\end{array}$ & $\begin{array}{l}\mathrm{LSI}>90 \% \text { or } \mathrm{LSI}>100 \% \text { for } \\
\text { pivoting/contact sports; A } \\
\text { battery of hop tests and } \\
\text { measurement of the quality of } \\
\text { the movement }\end{array}$ & $\begin{array}{l}\text { Sports specific training } \\
\text { without pain and giving } \\
\text { away (or fear of). Active gait } \\
\text { and symmetrical jogging. }\end{array}$ \\
\hline APTA $^{35}$ & $\begin{array}{l}\text { KOOS } \\
\text { IKDC } 2000 \\
\text { Lysholm Knee Scale } \\
\text { Marx Activity Level Scale } \\
\text { Tegner Activity Level } \\
\text { Scale } \\
\text { ACL-RSI }\end{array}$ & $\begin{array}{l}\text { Hop test LSI (single hop for distance, } \\
\text { triple hop for distance, crossover hop } \\
\text { for distance and 6-metre timed hop) }\end{array}$ & NR & $\begin{array}{l}\text { Hop test LSI (single hop for } \\
\text { distance, triple hop for distance, } \\
\text { crossover hop for distance and } \\
\text { 6-metre timed hop) }\end{array}$ & NR \\
\hline
\end{tabular}

AAOS, American Academy of Orthopaedic Surgeons; APTA, American Physical Therapy Association; CPG, clinical practice guideline; DOA, Dutch Orthopaedic Association; IKDC, International Knee Documentation Comitee; KNGF, Royal Dutch Society for Physical Therapy; KOOS, Knee injury and Osteoarthritis Outcome Score; K-SES, Knee Self-Efficacy Scale; LSI, Limb Asymmetry Index; MOON, Multicenter Orthopaedic Outcomes Network; NR, non-reported; NZGG, New Zealand Guidelines Group; PROM, patient-reported outcome measure; RSI, return to sport after injury; TSK-11, Tampa scale-11. 
developers to identify priorities, ensure viability and promote dissemination and adherence.

We strongly encourage guideline developers to consider the AGREE II framework when planning, developing and publishing CPGs. Two of the included CPGs (DOA, AAOS) used the AGREE instrument during the development phase ${ }^{36}$ or peer and public review of their guideline. ${ }^{33}$ Despite that DOA $\mathrm{CPG}^{36}$ used the AGREE instrument during the development phase, it had the lowest scores for the 'rigour of development', 'applicability' and 'editorial independence' domains.

The CPGs included in our review were mainly developed by orthopaedic or physiotherapy associations. CPGs that are developed by international organisations and governmental bodies score higher in most AGREE II domains. ${ }^{43}{ }^{53}$ We call for international cooperation to combine resources to develop one comprehensive and very high-quality CPG for this topic (post-ACL reconstruction rehabilitation). Such a CPG would eliminate redundancy, address the problem of applicability we identified and have broader reach than existing CPGs. ${ }^{53}$

\section{How can we move forward?}

We recommend international collaboration of orthopaedic surgeons and rehabilitation clinicians with all other relevant stakeholders (patients, coaches, insurance payers and funders, health-policy decision-makers, service workers, researchers and expert CPG developers) to harmonise and implement the best evidence available on postoperative ACL rehabilitation. Only one CPG (AAOS) ${ }^{33}$ considered the GRADE evidence rating tool to evaluate the strength of the evidence. The GRADE tool should be used in future CPGs. We strongly suggest that wording used to recommend rehabilitation approaches should be standardised to the strength of recommendations (as per GRADE) to guide rehabilitation (what clinicians should do/not do) and avoid be misinterpreted. After implementing CPGs, it is important to assess the extent to which CPGs reached the target groups and to identify shortcomings that require fine-tuning. ${ }^{54}$

\section{Strengths and limitations}

This is the first systematic review to identify and appraise CPGs on ACL rehabilitation. The AGREE II overall and domain reliability rates were higher than those previously reported in systematic reviews of CPGs on musculoskeletal conditions. ${ }^{29} 43$ This may be due to the narrower scope of the included CPGs and the meetings held before each AGREE II domain assessment, which may have reduced the often-reported subjectivity of user interpretation. ${ }^{55}$ Despite the potential limitations of our nonmultidisciplinary review team (reviewer bias), this contributed to a higher consistency in the appraisal as the two assessors have professional and academic backgrounds within the CPGs' scope and are thus more familiar with the subject.

The AGREE II scoring system relies on the intelligibility and comprehensiveness of the CPGs' reporting and does not reflect the clinical context or the quality and strength of the evidence. AGREE II does not provide an explicit cut-off to distinguish between high-quality and low-quality CPGs. We defined lowerquality CPGs or poor quality domains as those scoring lower than $50 \%$, based on previously convened high-quality and lowquality CPGs' cut-offs. ${ }^{31}$ We classified the recommendations as 'should be used', 'may be used' or 'should not be used', but we are not exempt from misinterpretation that may derive from heterogeneity in the formulation and wording of recommendations.

\section{CONCLUSION}

Considering overall quality and the applicability to ACL postoperative rehabilitation context, we recommend and endorse the use of the American Physical Therapy Association (APTA), Royal Dutch Society for Physical Therapy (KNGF) and Multicenter Orthopaedic Outcomes Network (MOON) CPGs. We call for international collaboration among relevant stakeholders to harmonise post-ACL reconstruction rehabilitation CPGs, promote their wider dissemination and adherence, and thus increase the quality of patient care/outcomes.

\section{What is already known}

Clinicians administer a variety of rehabilitation protocols after $\mathrm{ACL}$ reconstruction.

- High-quality clinical practice guidelines can improve clinical care.

\section{What are the new findings}

- Taken at face value (ie, without attending to quality), clinical practice guidelines (CPGs) recommended that immediate knee mobilisation and strength/neuromuscular training should be used. Early full weight-bearing exercises, early open and closed kinetic-chain exercises, cryotherapy and neuromuscular electrostimulation may be used according the individual circumstances. Continuous passive motion and functional bracing should not be used.

- The quality of the CPGs in ACL postoperative rehabilitation was generally good, but showed poor applicability (external validity) - meaning that the CPG may be difficult for clinicians to implement into clinical daily practice.

- We recommend international collaboration among relevant stakeholders (eg, expert CPG developers, clinicians of various stripes, health policy and service workers, patients) to create the 'Harmonised International Post ACL Reconstruction Rehabilitation CPG' to improve patient care and outcomes.

\section{Author affiliations}

${ }^{1}$ Clínica do Dragão, Espregueira-Mendes Sports Centre, FIFA Medical Centre of Excellence, Porto, Portugal

${ }^{2}$ Dom Henrique Research Centre, Porto, Portugal

${ }^{3}$ Faculty of Sports, University of Porto, Porto, Portugal

${ }^{4}$ Superior School of Health, University Fernando Pessoa, Porto, Portugal

${ }^{5}$ Sport Medisch Centrum Papendal, Arnhem, The Netherlands

${ }^{6}$ Radboud Institute for Health Sciences, IQ Healthcare, Radboud University Medical

Center, Nijmegen, The Netherlands

${ }^{7}$ Research Group Musculoskeletal Rehabilitation, HAN University of Applied Sciences, Nijmegen, The Netherlands

${ }^{8}$ School of Medicine, University of Minho, Braga, Portugal

${ }^{9}$ ICVS/3B's-PT Government Associate Laboratory, Braga/Guimarães, Portugal

Contributors RA and RP performed the database searches, data analysis and initial interpretation of results. RA was responsible for initial drafting of the article, assisted by RP and reviewed by all authors. RvC and JBS provided advice throughout the interpretation of data and manuscript drafting. All authors were involved in the conception, design and interpretation of data. All authors read and reviewed the manuscript critically for important intellectual content and approved the final version to be submitted.

Funding The authors have not declared a specific grant for this research from any funding agency in the public, commercial or not-for-profit sectors.

Competing interests None declared.

Patient consent for publication Not required.

Provenance and peer review Not commissioned; externally peer reviewed.

ORCID iD

Renato Andrade http://orcid.org/0000-0002-7636-7816 


\section{REFERENCES}

1 Moses B, Orchard J, Orchard J. Systematic review: annual incidence of ACL injury and surgery in various populations. Res Sports Med 2012;20:157-79.

2 Marx RG, Jones EC, Angel M, et al. Beliefs and attitudes of members of the American Academy of orthopaedic surgeons regarding the treatment of anterior cruciate ligament injury. Arthroscopy 2003;19:762-70.

3 Richmond JC, Lubowitz JH, Poehling GG. Prompt operative intervention reduces long-term osteoarthritis after knee anterior cruciate ligament tear. Arthroscopy 2011:27:149-52.

4 Ardern CL, Taylor NF, Feller JA, et al. Fifty-five per cent return to competitive sport following anterior cruciate ligament reconstruction surgery: an updated systematic review and meta-analysis including aspects of physical functioning and contextual factors. Br J Sports Med 2014;48:1543-52.

5 Filbay SR, Culvenor AG, Ackerman IN, et al. Quality of life in anterior cruciate ligament-deficient individuals: a systematic review and meta-analysis. Br J Sports Med 2015;49:1033-41.

6 Lie MM, Risberg MA, Storheim K, et al. What's the rate of knee osteoarthritis 10 years after anterior cruciate ligament injury? An updated systematic review. Br J Sports Med 2019. doi:10.1136/bjsports-2018-099751. [Epub ahead of print: 01 Apr 2019].

7 Grindem H, Snyder-Mackler L, Moksnes H, et al. Simple decision rules can reduce reinjury risk by $84 \%$ after $\mathrm{ACL}$ reconstruction: the Delaware-Oslo $\mathrm{ACL}$ cohort study. $\mathrm{Br}$ J Sports Med 2016;50:804-8.

8 Kyritsis $\mathrm{P}$, Bahr R, Landreau P, et al. Likelihood of $\mathrm{ACL}$ graft rupture: not meeting six clinical discharge criteria before return to sport is associated with a four times greater risk of rupture. Br J Sports Med 2016;50:946-51.

9 Ebert JR, Edwards P, Yi L, et al. Strength and functional symmetry is associated with post-operative rehabilitation in patients following anterior cruciate ligament reconstruction. Knee Surg Sports Traumatol Arthrosc 2018;26:2353-61.

10 Wiggins AJ, Grandhi RK, Schneider DK, et al. Risk of secondary injury in younger athletes after anterior cruciate ligament reconstruction: a systematic review and meta-analysis. Am J Sports Med 2016;44:1861-76.

11 Burgi CR, Peters S, Ardern CL, et al. Which criteria are used to clear patients to return to sport after primary ACL reconstruction? a scoping review. Br J Sports Med 2019. doi:10.1136/bjsports-2018-099982. [Epub ahead of print: 02 Feb 2019].

12 Adams D, Logerstedt DS, Hunter-Giordano A, et al. Current concepts for anterior cruciate ligament reconstruction: a criterion-based rehabilitation progression. J Orthop Sports Phys Ther 2012;42:601-14.

13 Rambaud AJM, Ardern CL, Thoreux P, et al. Criteria for return to running after anterior cruciate ligament reconstruction: a scoping review. Br J Sports Med 2018:52:1437-44

14 Makhni EC, Crump EK, Steinhaus ME, et al. Quality and variability of online available physical therapy protocols from academic orthopaedic surgery programs for anterior cruciate ligament reconstruction. Arthroscopy 2016;32:1612-21.

15 Arna Risberg M, Lewek M, Snyder-Mackler L. A systematic review of evidence for anterior cruciate ligament rehabilitation: how much and what type? Physical Therapy in Sport 2004;5:125-45.

16 Lobb R, Tumilty S, Claydon LS. A review of systematic reviews on anterior cruciate ligament reconstruction rehabilitation. Phys Ther Sport 2012;13:270-8.

17 Thrush C, Porter TJ, Devitt BM. No evidence for the most appropriate postoperative rehabilitation protocol following anterior cruciate ligament reconstruction with concomitant articular cartilage lesions: a systematic review. Knee Surg Sports Traumatol Arthrosc 2018;26:1065-73.

18 Valle C, Hirschmüller A, Schmitt-Sody M, et al. [Standards in rehabilitation following anterior cruciate ligament reconstruction in the German-speaking world]. Sportverletz Sportschaden 2018;32:103-10.

19 Greenberg EM, Greenberg ET, Albaugh J, et al. Rehabilitation practice patterns following anterior cruciate ligament reconstruction: a survey of physical therapists. J Orthop Sports Phys Ther 2018;48:801-11.

20 Ahmad SS, Meyer JC, Krismer AM, et al. Outcome measures in clinical ACL studies: an analysis of highly cited level I trials. Knee Surg Sports Traumatol ArthrosC 2017;25:1517-27.

21 Barber-Westin SD, Noyes FR. Objective criteria for return to athletics after anterior cruciate ligament reconstruction and subsequent reinjury rates: a systematic review. Phys Sportsmed 2011;39:100-10.

22 Webster KE, Hewett TE. What is the evidence for and validity of Return-to-Sport testing after anterior cruciate ligament reconstruction surgery? A systematic review and meta-analysis. Sports Med 2019:49:917-29.

23 Losciale JM, Zdeb RM, Ledbetter L, et al. The association between passing Return-toSport criteria and second anterior cruciate ligament injury risk: a systematic review with meta-analysis. J Orthop Sports Phys Ther 2019;49:43-54.

24 Liberati Aet al. The PRISMA statement for reporting systematic reviews and meta-analyses of studies that evaluate health care interventions: explanation and elaboration. Ann Intern Med 2009;151:W-65-94.

25 Nagatsuma K, Kawashima T, Ohmi Y, et al. Tutorial: guideline for physical therapy in patients with anterior cruciate ligament injury. Physical Therapy Japan 2015:42:604-13.
26 Steinberg E, Greenfield S, Wolman DM, et al. Clinical practice guidelines we can trust. National Academies Press, 2011

27 AGREE Collaboration. Development and validation of an international appraisal instrument for assessing the quality of clinical practice guidelines: the agree project. Qual Saf Health Care 2003;12:18-23.

28 Brouwers MC, Kho ME, Browman GP, et al. Agree II: advancing Guideline Development, reporting and evaluation in health care. CMAJ 2010;182:E839-E842.

29 Pincus D, Kuhn JE, Sheth U, et al. A systematic review and appraisal of clinical practice guidelines for musculoskeletal soft tissue injuries and conditions. Am J Sports Med 2017; 45:1458-64.

30 Isaac A, Saginur M, Hartling L, et al. Quality of reporting and evidence in American Academy of pediatrics guidelines. Pediatrics 2013;131:732-8.

31 Hoffmann-Eßer W, Siering U, Neugebauer EAM, et al. Systematic review of current guideline appraisals performed with the Appraisal of Guidelines for Research \& Evaluation II instrument-a third of AGREE II users apply a cut-off for guideline quality. J Clin Epidemiol 2018;95:120-7

32 Cicchetti DV. Guidelines, criteria, and rules of thumb for evaluating normed and standardized assessment instruments in Psychology

33 Shea KG, Carey JL. Management of anterior cruciate ligament injuries: evidence-based guideline. J Am Acad Orthop Surg 2015;23:e1-5.

34 Wright RW, Haas AK, Anderson J, et al. Anterior cruciate ligament reconstruction rehabilitation: moon quidelines. Sports Health 2015;7:239-43.

35 Logerstedt DS, Scalzitti D, Risberg MA, et al. Knee stability and movement coordination impairments: knee ligament sprain revision 2017. J Orthop Sports Phys Ther 2017;47:A1-47

36 Meuffels DE, Poldervaart MT, Diercks RL, et al. Guideline on anterior cruciate ligament injury: a multidisciplinary review by the Dutch orthopaedic association. Acta Orthop 2012:83:379-86.

37 van Melick N, van Cingel REH, Brooijmans F, et al. Evidence-based clinical practice update: practice guidelines for anterior cruciate ligament rehabilitation based on a systematic review and multidisciplinary consensus. Br J Sports Med 2016;50:1506-15.

38 Arroll B, Robb G, Sutich E. The diagnosis and management of soft tissue knee injuries: internal derangements, 2003: 1-100.

39 NTvG V. EBRO richtlijnen. Ned Tijdschr Geneesk 2005;149:213-4.

40 Martimbianco ALC, Gomes da Silva BN, de Carvalho APV, et al. Effectiveness and safety of cryotherapy after arthroscopic anterior cruciate ligament reconstruction. A systematic review of the literature. Phys Ther Sport 2014;15:261-8.

41 Ardern CL, Glasgow P, Schneiders A, et al. Consensus statement on return to sport from the first World Congress in sports physical therapy, Bern. Br J Sports Med 2016;2016:853-64.

42 Alonso-Coello P, Irfan A, Sola I, et al. The quality of clinical practice guidelines over the last two decades: a systematic review of guideline appraisal studies. BMJ Qual Saf 2010;19:e58.

43 Lin I, Wiles LK, Waller R, et al. Poor overall quality of clinical practice guidelines for musculoskeletal pain: a systematic review. Br J Sports Med 2018:52:337-43.

44 Scott H, Fawkner S, Oliver CW, et al. How to make an engaging infographic? Br J Sports Med 2017:51:1183-4.

45 Scott H, Fawkner S, Oliver C, et al. Why healthcare professionals should know a little about infographics. Br J Sports Med 2016:50:1104-5.

46 Barton CJ, Merolli MA. It is time to replace publish or perish with get visible or vanish: opportunities where digital and social media can reshape knowledge translation. $\mathrm{Br} J$ Sports Med 2019;53:594-8.

47 Free C, Phillips G, Watson L, et al. The effectiveness of mobile-health technologies to improve health care service delivery processes: a systematic review and meta-analysis. PLoS Med 2013;10:e1001363.

48 Ventola CL. Mobile devices and apps for health care professionals: uses and benefits. P T 2014;39:356-64.

49 Pluim BM. Watch and learn: educational videos at your finger tips. Br J Sports Med 2016;50:202-3.

50 Archambault PM, van de Belt TH, Grajales III FJ, et al. Wikis and collaborative writing applications in health care: a scoping review. J Med Internet Res 2013;15:e210.

51 Brown T, Findlay M, von Dincklage J, et al. Using a wiki platform to promote guidelines internationally and maintain their currency: evidence-based guidelines for the nutritional management of adult patients with head and neck cancer. J Hum Nutr Diet 2013;26:182-90

52 Armstrong MJ, Rueda J-D, Gronseth GS, et al. Framework for enhancing clinical practice guidelines through continuous patient engagement. Health Expect 2017;20:3-10.

53 Armstrong JJ, Goldfarb AM, Instrum RS, et al. Improvement evident but still necessary in clinical practice guideline quality: a systematic review. J Clin Epidemiol 2017:81:13-21.

54 Staal JB, Hlobil H, van Tulder MW, et al. Occupational health guidelines for the management of low back pain: an international comparison. Occup Environ Med 2003;60:618-26.

55 Scott NA, Moga C, Harstall C. Making the agree tool more user-friendly: the feasibility of a user guide based on Boolean operators. J Eval Clin Pract 2009:15:1061-73. 